\title{
Correlation between Xerostomia index, Clinical Oral Dryness Scale, and ESSPRI with different hyposalivation tests
}

This article was published in the following Dove Medical Press journal: Open Access Rheumatology: Research and Reviews

\author{
Ola Hijjaw' \\ Mohammad Alawneh' \\ Khaled Ojjoh' \\ Hazem Abuasbeh' \\ Ahmad Alkilany' \\ Nabeel Qasem' \\ Mohammad Al-Essa' \\ Saif Aldeen AIRyalat ${ }^{2}$ \\ 'Department of Internal Medicine, \\ The University of Jordan, Amman \\ I 1942, Jordan; ${ }^{2}$ Department of \\ Ophthalmology, The University of \\ Jordan, Amman I 1942, Jordan
}

Correspondence: Saif Aldeen AIRyalat Department of Ophthalmology, The University of Jordan, Queen Rania str., Amman I 1942, Jordan

Tel +962798914594

Email saifryalat@yahoo.com
Background and objective: Xerostomia is a subjective measure of dry mouth, while hyposalivation is an objective measure of reduced saliva flow rate. In this study, we aim to assess the association between commonly used xerostomia scoring systems, with different hyposalivation measures among Sjogren Syndrome (SS) patients.

Methods: In a cohort of SS patients, we assessed xerostomia using Xerostomia index, clinical oral dryness scale (CODS), and the European League Against Rheumatism SS Patient-Reported Index (ESSPRI), and we assessed hyposalivation using unstimulated whole saliva flow (UWS), stimulated whole saliva flow (SWS), and stimulated parotid flow (SPF). We analyzed the association between xerostomia and hyposalivation using association tests in SPSS.

Results: We included a total of 49 patients in this study, of which 34 (68\%) had primary SS, and $15(32 \%)$ had secondary. CODS was significantly correlated with SWS ( $P=0.048)$, with a negative correlation coefficient of 0.216 , and with SPF $(P=0.009)$, with a negative correlation coefficient of 0.291 . The dryness domain of ESSPRI was significantly correlated with UWS $(P=0.031)$ with a negative correlation coefficient of 0.233 .

Conclusion: CODS is the scoring system with the highest correlation with hyposalivation, particularly SWS and SPF, followed by ESSPRI dry domain, which is correlated with UWS. Xerostomia index is not correlated with hyposalivation.

Keywords: Sjogren syndrome, xerostomia, hyposalivation, XI, CODS, ESSPRI

\section{Introduction}

Sjogren's syndrome (SS) is a chronic autoimmune disease affecting mainly the exocrine glands, especially the lacrimal and salivary glands. It is the second most common autoimmune rheumatic disease. ${ }^{1}$ Its prevalence ranges between $0.1 \%$ and $4.8 \%$ with a female to male ratio of 9:1, mostly in the age of 40-60 years. ${ }^{2}$ Generally, SS is classified into primary SS, which occurs alone without any other associated disease, and secondary SS, which is associated with other diseases such as rheumatoid arthritis and systemic lupus erythematosus. ${ }^{3} \mathrm{SS}$ has a wide variety of presentations and can affect almost any organ, but it typically presents with dryness of eyes and mouth. ${ }^{4}$

Xerostomia and hyposalivation are two concepts used in the diagnostic criteria of SS, which are distinguishable from each other. Xerostomia is a subjective measure, when the patient reports a daily feeling of dry mouth, while hyposalivation is an objective quantifiable measure of reduced saliva flow rate. ${ }^{5}$ Multiple scoring system has been developed to assess xerostomia and several tests for hyposalivation. Three scoring systems we will discuss in our study include Xerostomia index (XI), clinical oral dryness scale (CODS), and the European League Against Rheumatism SS Patient-Reported Index 
(ESSPRI). ${ }^{6-8}$ Other scoring systems include Profile of Fatigue and Discomfort (PROFAD) ${ }^{9}$ and Sicca Symptoms Inventory (SSI). ${ }^{10}$ The idea behind PROFAD and SSI development was that the main symptoms of patients with SS are dryness, pain, somatic, and mental fatigue, so these scores were developed to assess these symptoms - PROFAD for fatigue and discomfort and SSI for evaluation of dryness features.

On the other hand, hyposalivation can be assessed either without saliva stimulation (unstimulated whole saliva flow [UWS]) or with saliva stimulation (stimulated whole saliva flow [SWS] and stimulated parotid flow [SPF]), each of which has its own characteristic features. ${ }^{11}$ For instance, stimulated flow is less subjected to variation more than unstimulated tests, while stimulated tests are sometimes difficult to obtain. ${ }^{11,12}$ Although the main concern for clinical practitioners is xerostomia rather than hyposalivation, ${ }^{5}$ previous studies stressed on the strong relationship between hyposalivation and general health. ${ }^{13}$ In this study, we aim to find the association of commonly used xerostomia assessment scores, including XI, CODS, and ESSPRI, with different hyposalivation tests.

\section{Methods}

This study's data were obtained from the randomized controlled trials that studied the effect of sialendoscopy on salivary gland function in patients with $\mathrm{SS},{ }^{14,15}$ registered at the US National Institutes of Health (ClinicalTrials.gov; number: NCT02112019).

\section{Participants}

This study included patients aged 18-75 years who were diagnosed with SS based on the 2002 American-European Consensus Group classification criteria. ${ }^{16}$ Exclusion criteria were as follows:

1. Patients with acute sialadenitis

2. Severe illness

3. Physical conditions interfering with a treatment under general anesthesia

4. History of head and neck radiotherapy

All patients signed a written consent.

\section{Variables studied}

Upon enrolment, each patient provided his/her demographic data regarding age and gender, and underwent the following tests to assess hyposalivation:

1. UWS: patients were instructed to start collecting saliva immediately after an initial swallow, and subsequently expectorate into a pre-weighed container every $30 \mathrm{sec}-$ onds for a 5-minute period.

2. SWS: patients were asked to chew a $5 \times 5 \mathrm{~cm}$ sheet of paraffin (Parafilm M, Pechiney, Chicago, IL, USA) and expectorate into a pre-weighed container every $30 \mathrm{sec}-$ onds during a 5-minute period.

3. SPF: collected in plastic tubes from each parotid gland using modified Lashley cups. Stimulation with citric acid $(2 \% \mathrm{w} / \mathrm{v})$ was applied with a cotton wool swab to the lateral border of the tongue at 30 -second intervals.

Patients were instructed to refrain from eating/chewing, drinking, brushing teeth, and smoking for 90 minutes prior to these tests.

Also the following questionnaires were used to assess xerostomia:

1. Xerostomia inventory: ${ }^{6}$ an 11 -item score with responses from "Never" to "Always" in a Likert scale. A high total score indicates extremely dry mouth.

2. Clinical Oral Dryness Scale: ${ }^{7}$ a 10-point clinical scale, with a score of 1 assigned to each item. A high total score indicates increased xerostomia severity.

3. European League Against Rheumatism SS PatientReported Index: ${ }^{8}$ a 10-point scale for each of oral dryness, pain, and fatigue domains. As we are comparing xerostomia assessment questionnaires, only dryness domain was included. A high total dryness domain score indicates increased xerostomia severity.

\section{Statistical analysis}

We used SPSS version 21.0 (Chicago, IL, USA) in our analysis. We used mean ( \pm SD) to describe age, UWS, SWS, and SPF. We used count (frequency) to describe gender, and primary or secondary SS.

As the data are nonlinear and nonmonotonically distributed, we used Kendall's tau test to analyze the correlation between USS, SWS, and SPF and the total score of CODS, XI, and ESSPRI. Moreover, we used Kendall's tau test to find the correlation between the questionnaires (CODS, XI, and ESSPRI). We reported the results in terms of correlation coefficient and its significance level. A $P$-value of $<0.05$ was used as the significant threshold.

\section{Results}

We included a total of 49 patients in this study with a mean age of $59( \pm 10.4)$ years. There were $43(87.8 \%)$ women and $6(12.3 \%)$ men. Thirty-four $(68 \%)$ had primary SS. The mean UWS was $0.14( \pm 0.15) \mathrm{mL} / \mathrm{min}$, 
SWS was $0.46( \pm 0.44) \mathrm{mL} / \mathrm{min}$, and SPF was $0.22( \pm 0.26)$ $\mathrm{mL} / \mathrm{min}$.

CODS was significantly correlated with SWS $(P=0.048)$, with a negative correlation coefficient of 0.216 , and with SPF ( $P=0.009$ ), with a negative correlation coefficient of 0.291 .

The dryness domain of ESSPRI was significantly correlated with UWS $(P=0.031)$ with a negative correlation coefficient of 0.233 . Figures $1-3$ show the correlations of CODS vs SWS, CODS vs SPF, and ESSPRI vs UWS, respectively.

Only XI and dryness domain of ESSPRI were significantly correlated $(P<0.001)$ with a positive correlation coefficient of 0.546 . The correlation between the three tools involved is shown in Figure 4. We did not find significant age or gender differences regarding either USS, SWS, and SPF, or the total score of CODS, XI, and ESSPRI.

\section{Discussion}

Upon comparing the association between XI, CODS, and dryness domain of ESSPRI with hyposalivation measuring tests, CODS significantly and negatively correlated with stimulating flow tests (SWS, SPF), whereas dryness domain of ESSPRI significantly and negatively correlated with the

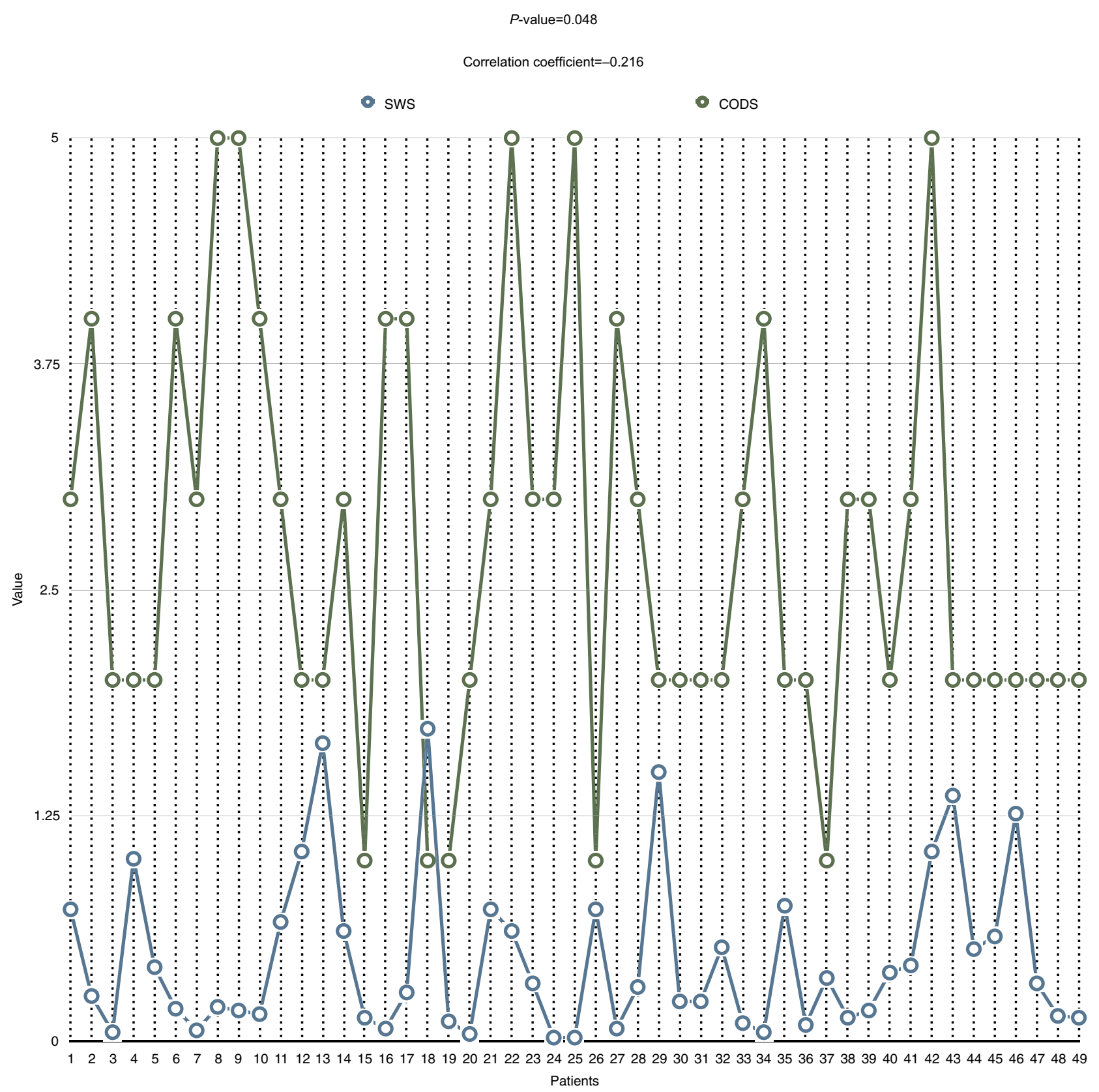

Figure I Correlation between CODS and SWS, where each vertical line represents a patient. Abbreviations: CODS, clinical oral dryness scale; SWS, stimulated whole saliva flow. 


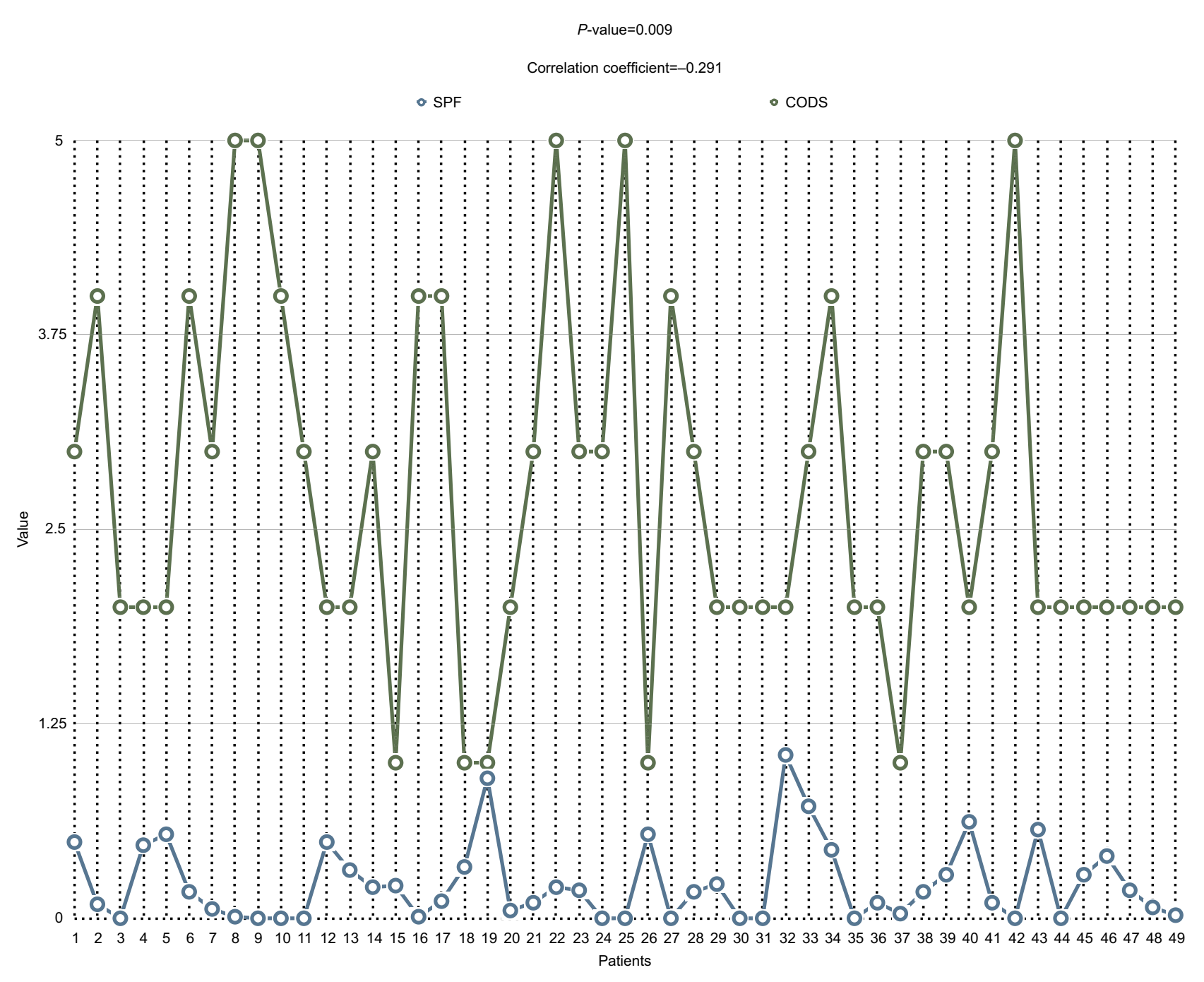

Figure 2 Correlation between CODS and SPF, where each vertical line represents a patient.

Abbreviations: CODS, clinical oral dryness scale; SPF, stimulated parotid flow.

UWS. For XI, we did not find significant correlation with any hyposalivation tests (Table 1).

$\mathrm{XI}$ is an 11-item questionnaire designed by Thomson et al. ${ }^{6}$ The primary aim of developing XI was to assess elderly individuals' risk of developing dental caries from xerostomia. When it was first developed and tested on normal elderly patients, XI score was not found to correlate with hyposalivation, as measured by UWS, ${ }^{6}$ a finding in concordance with this study that included SS patients, where we also did not find a significant correlation with SWS or SPF. Contrary to our findings, several previous studies on patients with primary SS found a negative significant correlation between total XI score and both UWS and SWS. ${ }^{17,18}$ As it was developed in 1999, it was validated in different languages including Spanish, ${ }^{19}$ Portuguese, ${ }^{18}$ Dutch, ${ }^{20}$ Greek, ${ }^{21}$ Korean, ${ }^{17}$ and Chinese. ${ }^{22}$
CODS developed by Osailan et $\mathrm{al}^{7}$ is a 10-point scale that can be incorporated into the routine clinical assessment of dry mouth patients, based on ten key features of dry mouth, accompanied by example images. It allocates one point for each feature, with a low CODS score (0-3) indicating mild oral dryness and a high CODS score (7-10) indicating severe oral dryness. CODS was originally developed to assess dry mouth symptoms and to correlate with hyposalivation objective measures, including UWS and SPF, where the total CODS score was significantly higher in patients with low flow rate as measured by UWS and SPF.7 In our study on SS patients, we found a negative significant correlation between total CODS score and SWS and SPF, but not with UWS. Tashbayev et al investigated the correlation of different findings in primary SS patients, and they found a strong negative correlation between CODS and both UWS and 


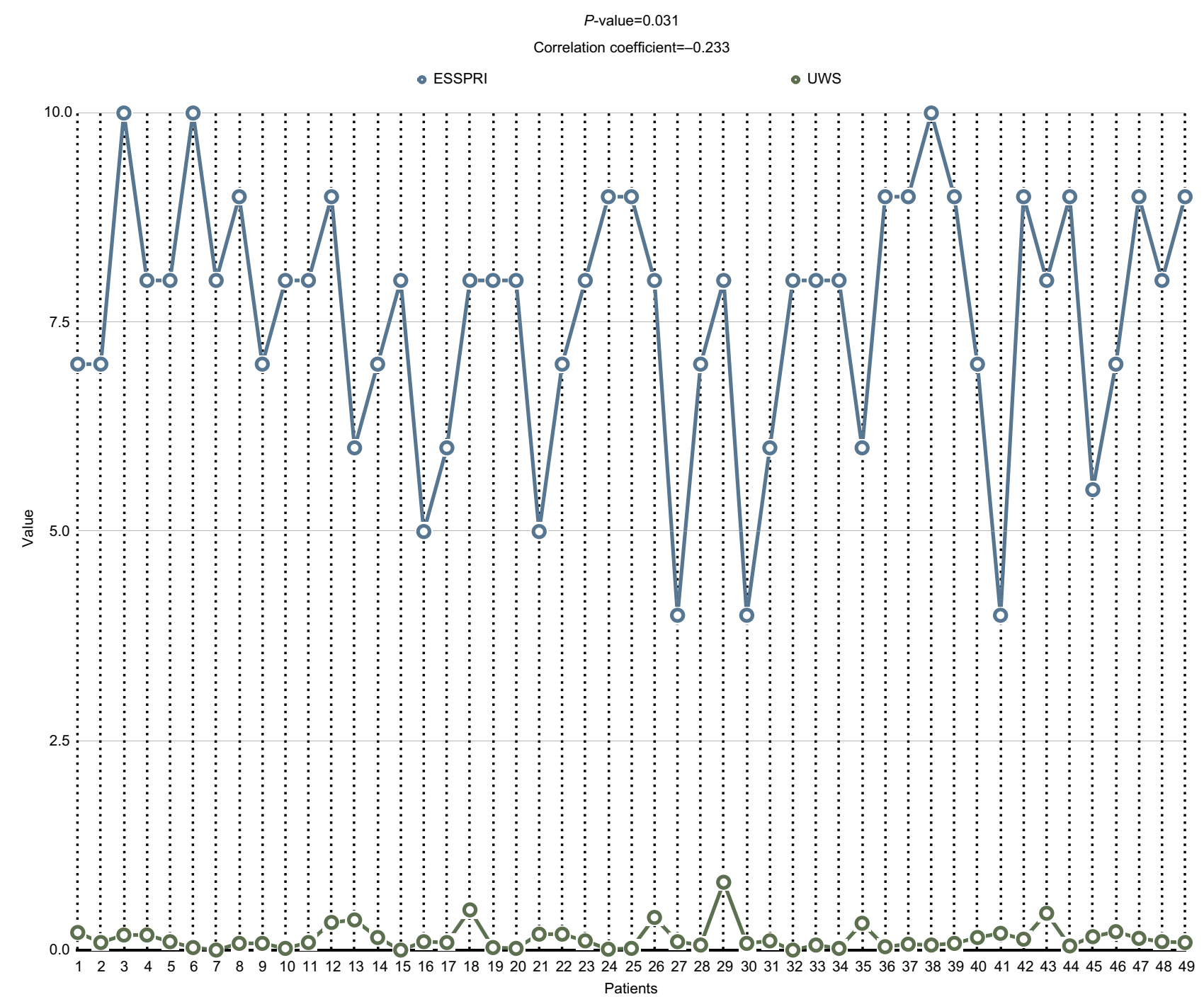

Figure 3 Correlation between ESSPRI and UWS, where each vertical line represents a patient.

Abbreviations: ESSPRI, European League Against Rheumatism SS Patient-Reported Index; SS, Sjogren's syndrome; UWS, unstimulated whole saliva flow.

SWS. ${ }^{23}$ Recently, Jager et al investigated the reliability of using CODS as a screening tool for oral dryness, and found a strong negative correlation between CODS total score and both UWS and SWS, where they tested SWS via both chewing stimulation and citric acid stimulation. ${ }^{24}$ Whereas, in this study, we found that CODS total score correlated only with ESSPRI dryness domain, Jager et al found that CODS significantly correlated with XI. ${ }^{24}$

ESSPRI is a patient index designed by the European league against rheumatism in $2011^{10}$ to measure patient's symptoms in primary SS, with participation of a large multinational panel of patients with primary SS. It consists of four domains: dryness, pain, somatic, and mental fatigue with a single $0-10$ numerical scale for each domain. Dryness features include (ocular, oral, skin, nasal, tracheal, and vaginal). The main strength of this recently devel- oped questionnaire is the multinational panel of patients included for its development, including patients from European, and both North and South American countries. ${ }^{25}$ This finding further supported the use of this instrument in intervention studies and in clinical practice. ${ }^{26} \mathrm{~A}$ main drawback of the primary ESSPRI study is that it did not involve objective assessment of dryness, which precludes the comparison with ours. A previous study that included patients with primary SS did not find a clear association between ESSPRI score and SWS flow, ${ }^{27}$ which is in concordance with our study. Furthermore, we found a significant negative correlation between ESSPRI dryness domain score and UWS flow.

Interestingly, ESSPRI total score correlated with both $\beta 2$ microglobulin and erythrocyte sedimentation rate. ${ }^{28}$ ESSPRI was recently validated in Portuguese population. ${ }^{29}$ 


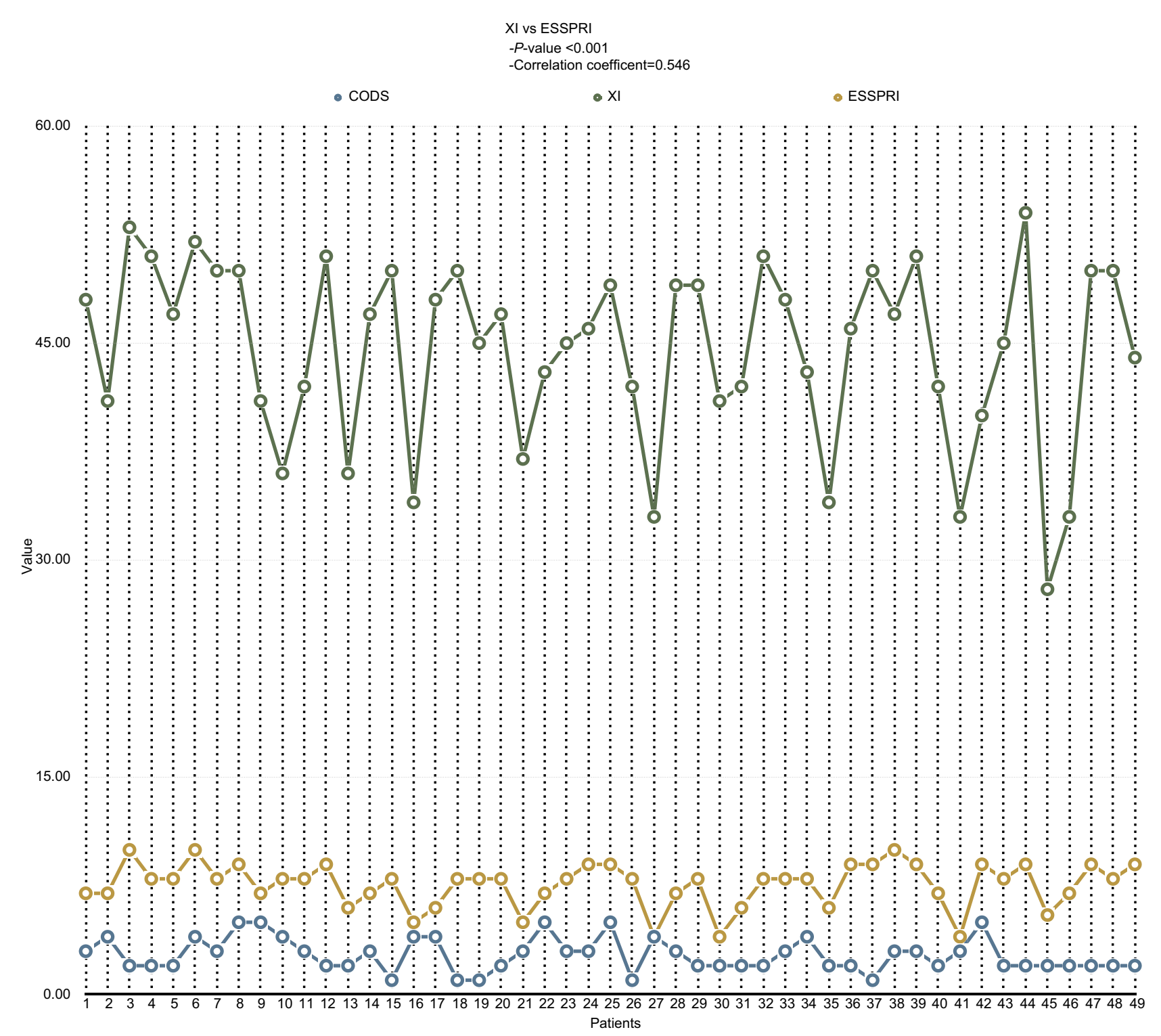

Figure 4 The correlation between the three tools involved: XI, CODS, and ESSPRI.

Abbreviations: CODS, clinical oral dryness scale; ESSPRI, European League Against Rheumatism SS Patient-Reported Index; SS, Sjogren's syndrome; XI, Xerostomia inventory.

Table I Comparing the characteristics of different xerostomia scores: $\mathrm{XI}, \mathrm{CODS}$, and the ESSPRI

\begin{tabular}{|l|l|l|l|}
\hline & XI & CODS & $\begin{array}{l}\text { ESSPRI dry } \\
\text { domain }\end{array}$ \\
\hline $\begin{array}{l}\text { Published year } \\
\text { Original patients } \\
\text { of interest } \\
\text { Questionnaire } \\
\text { reporting } \\
\text { Correlation with } \\
\text { salivary flow } \\
\begin{array}{l}\text { Number of } \\
\text { items } \\
\text { Validations }\end{array}\end{array}$ & $\begin{array}{l}1998 \\
\text { Elderly dental } \\
\text { patients } \\
\text { Patient }\end{array}$ & $\begin{array}{l}2012 \\
\text { Any patient }\end{array}$ & $\begin{array}{l}2010 \\
\text { SS }\end{array}$ \\
\hline
\end{tabular}

Abbreviations: CODS, clinical oral dryness scale; ESSPRI, European League Against Rheumatism SS Patient-Reported Index; SPF, stimulated parotid flow; SS, Sjogren's syndrome; SWS, stimulated whole saliva flow; UWS, unstimulated whole saliva flow; $\mathrm{XI}$, Xerostomia index.
The main limitation in this study is the absence of a control group to compare the results found in SS patients. Moreover, the sample population for future studies should be further increased to validate this study's findings. We believe future cohort studies should consider the assessment of other questionnaires, including SSI, ${ }^{10}$ in addition to increasing the sample size to validate the results found in the present study. Moreover, future studies should consider assessing systemic symptom questionnaires similar to PROFAD. ${ }^{30}$

\section{Conclusion}

This study provided a comparison between three tools used in the assessment of xerostomia in SS patients. The newly developed CODS is associated with stimulated salivary 
flow tests (ie, SWS and SPF). XI is not correlated with any objective hyposalivation tests. Finally, ESSPRI dryness domain is associated with the UWS. This is the first study to compare the three tools together, which will guide prospective researchers in choosing the best tool according to their study aim.

\section{Data sharing statement}

Data are available upon request from: Karagozoglu KH, Vissink A, Forouzanfar T, Brand HS, Maarse F, Jager DHJ (2018) Data from: Sialendoscopy enhances salivary gland function in Sjögren's syndrome: a 6 month follow-up, randomized and controlled, single blind study. Dryad Digital Repository. https://doi.org/10.5061/dryad.r7m1n

\section{Disclosure}

The authors report no conflicts of interest in this work.

\section{References}

1. Tincani A, Andreoli L, Cavazzana I, et al. Novel aspects of Sjögren's syndrome in 2012. BMC Med. 2013;11:93.

2. Reksten TR, Jonsson MV. Sjögren's syndrome: an update on epidemiology and current insights on pathophysiology. Oral Maxillofac Surg Clin North Am. 2014;26(1):1-12.

3. Mavragani CP, Moutsopoulos HM. Sjögren syndrome. CMAJ. 2014;186(15):E579-E586.

4. Carr AJ, Ng WF, Figueiredo F, Macleod RI, Greenwood M, Staines K. Sjögren's syndrome - an update for dental practitioners. Br Dent J. 2012;213(7):353-357.

5. Nederfors T. Xerostomia and hyposalivation. Adv Dent Res. 2000;14:48-56.

6. Thomson WM, Chalmers JM, Spencer AJ, Williams SM. The Xerostomia Inventory: a multi-item approach to measuring dry mouth. Community Dent Health. 1999;16(1):12-17.

7. Osailan SM, Pramanik R, Shirlaw P, Proctor GB, Challacombe SJ. Clinical assessment of oral dryness: development of a scoring system related to salivary flow and mucosal wetness. Oral Surg Oral Med Oral Pathol Oral Radiol. 2012;114(5):597-603.

8. Seror R, Ravaud P, Bowman SJ, et al; EULAR Sjögren's Task Force. EULAR Sjogren's syndrome disease activity index: development of a consensus systemic disease activity index for primary Sjogren's syndrome. Ann Rheum Dis. 2010;69(6):1103-1109.

9. Bowman SJ, Booth DA, Platts RG; UK Sjögren's Interest Group. Measurement of fatigue and discomfort in primary Sjogren's syndrome using a new questionnaire tool. Rheumatology (Oxford). 2004;43(6):758-764

10. Bowman SJ, Booth DA, Platts RG, Field A, Rostron J; UK Sjögren's Interest Group. Validation of the Sicca Symptoms Inventory for clinical studies of Sjögren's syndrome. J Rheumatol. 2003;30(6):1259-1266.

11. Humphrey SP, Williamson RT. A review of saliva: normal composition, flow, and function. J Prosthet Dent. 2001;85(2):162-169.

12. Speight PM, Kaul A, Melsom RD. Measurement of whole unstimulated salivary flow in the diagnosis of Sjögren's syndrome. Ann Rheum Dis. 1992;51(4):499-502.
13. Flink H, Bergdahl M, Tegelberg A, Rosenblad A, Lagerlöf F. Prevalence of hyposalivation in relation to general health, body mass index and remaining teeth in different age groups of adults. Community Dent Oral Epidemiol. 2008;36(6):523-531.

14. Karagozoglu KH, Vissink A, Forouzanfar T, Brand HS, Maarse F, Jager DHJ. Sialendoscopy enhances salivary gland function in Sjögren's syndrome: a 6-month follow-up, randomised and controlled, single blind study. Ann Rheum Dis. 2018;77(7):1025-1031.

15. Karagozoglu KH, Vissink A, Forouzanfar T, Brand HS, Maarse F, Jager DHJ. Sialendoscopy enhances salivary gland function in Sjögren's syndrome: a 6 month follow-up, randomized and controlled, single blind study. Dryad Digital Repository. 2018.

16. Vitali C, Bombardieri S, Jonsson R; European Study Group on Classification Criteria for Sjögren's Syndrome. Classification criteria for Sjögren's syndrome: a revised version of the European criteria proposed by the American-European Consensus Group. Ann Rheum Dis. 2002;61(6):554-558.

17. Lee J, Koh JH, Kwok SK, Park SH. Translation and validation of a Korean version of the Xerostomia Inventory in patients with primary Sjögren's Syndrome. J Korean Med Sci. 2016;31(5):724-728.

18. da Mata AD, da Silva Marques DN, Freitas FM, et al. Translation, validation, and construct reliability of a Portuguese version of the Xerostomia Inventory. Oral Dis. 2012;18(3):293-298.

19. Serrano C, Fariña MP, Pérez C, Fernández M, Forman K, Carrasco M. Translation and validation of a Spanish version of the xerostomia inventory. Gerodontology. 2016;33(4):506-512.

20. Thomson WM, van der Putten GJ, de Baat C, et al. Shortening the Xerostomia Inventory. Oral Surg Oral Med Oral Pathol Oral Radiol Endod. 2011;112(3):322-327.

21. Gkavela G, Kossioni A, Lyrakos G, Karkazis H, Volikas K. Translation and preliminary validation of the Greek version of the Xerostomia Inventory in older people. Eur Geriatr Med. 2015;6(3):237-240.

22. He SL, Wang JH, Li M. Validation of the Chinese version of the Summated Xerostomia Inventory (SXI). Qual Life Res. 2013;22(10):2843-2847.

23. Tashbayev B, Rusthen S, Young A, et al. Interdisciplinary, comprehensive oral and ocular evaluation of patients with primary Sjögren's syndrome. Sci Rep. 2017;7(1):10761.

24. Jager DHJ, Bots CP, Forouzanfar T, Brand HS. Clinical oral dryness score: evaluation of a new screening method for oral dryness. Odontology. 2018;106(4):439-444.

25. Seror R, Theander E, Bootsma H, et al. Outcome measures for primary Sjögren's syndrome: a comprehensive review. JAutoimmun. 2014;51:51-56.

26. Lendrem D, Mitchell S, McMeekin P, et al; UK primary Sjögren's Syndrome Registry. Do the EULAR Sjögren's syndrome outcome measures correlate with health status in primary Sjögren's syndrome? Rheumatology (Oxford). 2015;54(4):655-659.

27. Meiners PM, Arends S, Brouwer E, Spijkervet FK, Vissink A, Bootsma $\mathrm{H}$. Responsiveness of disease activity indices ESSPRI and ESSDAI in patients with primary Sjögren's syndrome treated with rituximab. Ann Rheum Dis. 2012;71(8):1297-1302.

28. Pertovaara M, Korpela M. ESSPRI and other patient-reported indices in patients with primary Sjogren's syndrome during 100 consecutive outpatient visits at one rheumatological clinic. Rheumatology (Oxford). 2014;53(5):927-931.

29. Paganotti MA, Valim V, Serrano ÉV, Miyamoto ST, Giovelli RA, Santos MC. Validation and psychometric properties of the EULAR Sjögren's Syndrome Patient Reported Index (ESSPRI) into Brazilian Portuguese. Rev Bras Reumatol. 2015;55(5):439-445.

30. Vitali C, Palombi G, Baldini C, et al. Sjögren's Syndrome Disease Damage Index and disease activity index: scoring systems for the assessment of disease damage and disease activity in Sjögren's syndrome, derived from an analysis of a cohort of Italian patients. Arthritis Rheum. 2007;56(7):2223-2231. 


\section{Publish your work in this journal}

Open Access Rheumatology: Research and Reviews is an international, peerreviewed, open access journal publishing original research, reports, editorials, reviews and commentaries on all aspects of clinical and experimental rheumatology in the clinic and laboratory including the following topics: Pathology, pathophysiology of rheumatological diseases; Investigation, treatment and management of rheumatological diseases; Clinical trials and novel pharmacological approaches for the treatment of rheumatological disorders. The manuscript management system is completely online and includes a very quick and fair peer-review system, which is all easy to use. Visit http://www.dovepress.com testimonials.php to read real quotes from published authors. 